\title{
Occupational therapy and gerontology: an analysis of scientific production in south america
}

\begin{abstract}
As a result of population aging, countries have increasingly sought to understand this process and in this sense, research in the area is becoming more relevant in the different professions. The main objective of this study was to delineate a panorama of the scientific production in occupational therapy in gerontology, published as an article in the main occupational therapy journals in South America. It was a study of bibliographic review of a qualitative-quantitative approach in the main specific publications of the Occupational Therapy area of South America. The publications were categorized and discussed around the following aspects: "Therapeutic Resources", "Social, Cultural and Economic Affairs"; "Health/Disease Process", "Caregivers", "Institutionalized /Hospitalized"; "Quality of life" and "other aging issues". It was concluded that, with the analysis of the bibliographical production of occupational therapists, the aging was approached on several aspects, although with a certain emphasis on the resources and techniques of the profession.
\end{abstract}

Keywords: occupational therapy, geriatrics, elderly, aging, review

\author{
Volume 4 Issue 5 - 2019
}

\author{
Maria das Graças Ferreira Valente,' Claudia \\ Reinoso Araujo de Carvalho ${ }^{2}$ \\ 'Occupational Therapist, Federal University of Rio de Janeiro, \\ Brazil \\ ${ }^{2}$ Adjunct Professor, Department of Occupational Therapy, PhD \\ in Public Health, Postdoctoral in Occupational Therapy, Federal \\ University of Rio de Janeiro, Brazil
}

Correspondence: Claudia Reinoso Araujo de Carvalho, Adjunct Professor, Department of Occupational Therapy,PhD in Public Health. Postdoctoral in Occupational Therapy, Federal University of Rio de Janeiro, Brazil, Tel (2I)39386506, (2I)988966438, Email claudiareinoso73@gmail.com

Received: October 02, 2019 | Published: October 10, 2019

\section{Introduction}

According to the United Nations (UN), 73.5 million people aged 60 and over live in Latin America and the Caribbean, representing $11.5 \%$ of the region's population. It is predicted that by 2050 this number will rise to 200 million, or $26 \%$ of the local population. ${ }^{1}$

As a result of population aging, countries are increasingly seeking to understand this process, seeking alternatives to "keep their elderly citizens socially and economically integrated and independent".,3 In this sense, research in the area is becoming increasingly relevant.

Aging is a multidimensional process and therefore generates complex demands. Older people constitute a significant portion of users of health services, social assistance and are increasingly important in social life. ${ }^{4}$ Thus, research involving the elderly develops in the most different themes among the different professions. According to Mendonça, ${ }^{5}$ in Gerontology, the Occupational Therapist participates in disease prevention and health maintenance programs, preparing the elderly for the events inherent to their aging.

The main objective of this study was to delineate an overview of the scientific production in occupational therapy at the interface with gerontology, published as an article in the main journals of South America. It was sought, above all, to characterize the tendency of publications in the area, identifying the quantity of publications, as well as their main themes.

\section{Method}

This was a literature review study with a qualitative approach. The search for publications was performed directly on the website of the main journals in the Occupational Therapy area of South America. They were: "Cadernos Brasileiro da Terapia ocupacional", "Revista de Terapia Ocupacional da USP"; "Revista Chilena de Terapia
Ocupacional"; "Revista Argentina de Terapia Ocupacional"; "Revista Interinstitucional Brasileira de Terapia Ocupacional" and 'Revista Ocupación Humana". The review was made considering the 10-year period, therefore, from 2009 to April 2019.

\section{Results}

Of the 1225 articles published by the journals considered in the study, 80 were in Gerontology. After analyzing the content of the abstracts, they were categorized around 7 main themes: "Therapeutic Resources", "Social, Cultural and Economic Affairs"; "Health/Disease Process", "Caregivers", "Institutionalized/Hospitalized"; "Quality of life" and "other aging issues" (Figure 1) (Figure 2) (Figure 3).

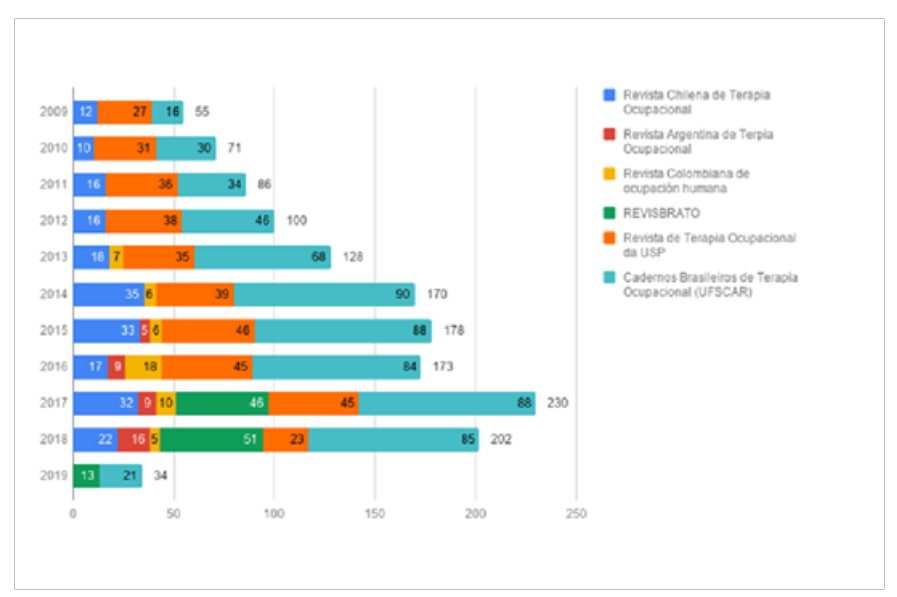

Figure I Total articles published by journals (2009-20I9). 


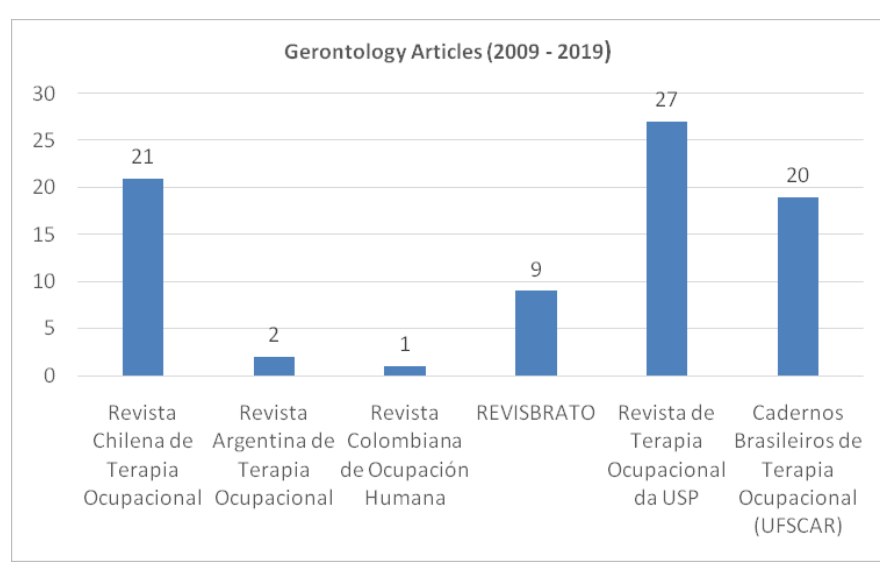

Figure 2 Gerontology articles (2009-2019).

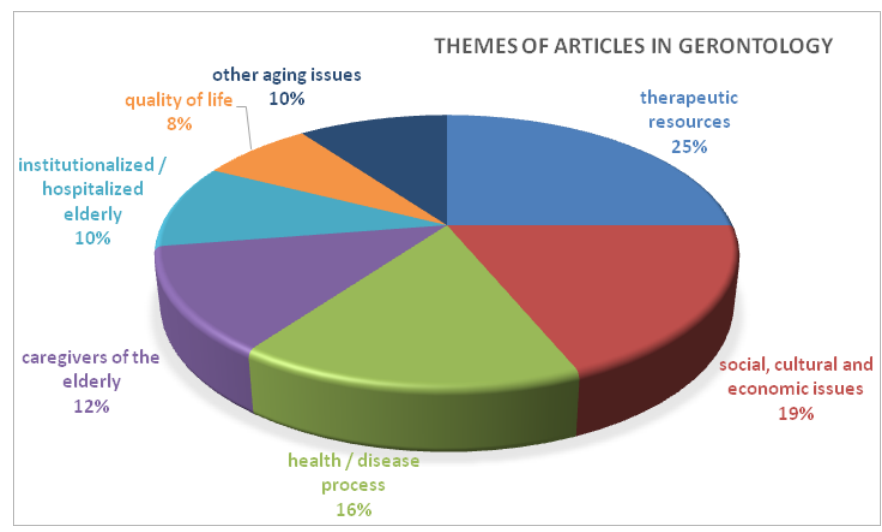

Figure $\mathbf{3}$ Themes of articles in gerontology.

\section{Discussion}

Brazilian production stands out from other South American countries, which is due to the fact that it has the largest number of journals, almost all indexed in the LILACS database (Latin American and Caribbean Health Sciences Literature), and one of them newly indexed in Scielo. Except for Brazilian journals, only the Chilean Journal of Occupational Therapy is indexed in the LILACS database and is in the process of claiming its indexation in Scielo (Scientific Electronic Library Online). The articles in the area of gerontology addressed different subjects, which denotes the interest of occupational therapists for various aspects inherent to aging.

Among the analyzed articles, 20 had as their main subject the therapeutic resources, evaluative and techniques used in the various actions of occupational therapists with the elderly. Corporal activities were a resource often mentioned in the publications.

With the theme "social, cultural and economic issues", 15 articles were analyzed, in which we highlight studies related to tourism, the community modalities of insertion of the occupational therapist, the changes in the routines and occupational roles of the elderly after the retirement process.
The health/disease process was the main theme of 13 of the articles analyzed. The most commonly addressed disease was Alzheimer's disease. Chronic diseases were also addressed, especially emphasizing joint pathologies and the impact on functionality. Parkinson's disease was also highlighted in the studies.

Ten of the articles considered in this study dealt with caregivers of the elderly. Regarding the institutionalized/ hospitalized elderly, this theme was cited by eight articles, which discussed the possible repercussions of illness and hospitalization on the occupations of the elderly, studied the functionality of institutionalized elderly, the cognitive profile and work in this approach.

The theme "quality of life" was addressed by six of the articles analyzed. The use of public transportation as an instrumental activity that enables the mobility of the elderly in the community and the factors that affect the social participation of the elderly were addressed.

Another 8 studies depicting subjects that were not characterized in the previous themes were about policies for the elderly in Brazil; professional training of the occupational therapist in gerontology; stereotypes related to the elderly and the perception of graduates of the occupational therapy course on the issue of aging.

\section{Final considerations}

The study made possible a synthesis of the scientific production of occupational therapists in South America in the area of gerontology and showed that this production is vast, corresponding to $5.67 \%$ within the total of articles published in the most diverse areas of practice of the profession.

The analysis of the bibliographic production of occupational therapists showed that aging was approached on several aspects by the authors, although with some emphasis on the resources and techniques of the profession.

\section{Acknowledgments}

None.

\section{Conflicts of interest}

The authors of this manuscript have no competing interests.

\section{References}

1. Economic committee for latin america and the caribbean. Social panorama of latin america and the caribbean. Santiago de Chile: ECLAC; 2016.

2. Kalache A. The world grows old: it is imperative to create a social solidarity pact. Public health science. 2008;13(4):1107-1111.

3. Miranda GMD, Mendes ACG, Silva ALA. Brazilian population aging: current and future social challenges and consequences. Rev bras geriatr gerontol. 2016;19(3):507-519.

4. Schimidt TCG, Silva MJP. Perception and understanding of health professionals and undergraduates about the elderly and human aging. Rev esc sick USP. 2012;46(3):612-617.

5. Mendonça JMB. Dependency and the elderly: meaning and policies. Kairós Journal - Gerontology. 2015;20(2):59-78. 